\title{
Dimensões práxica, ética e estética da formação docente: uma perspectiva à luz do pensamento Bakhtiniano
}

\author{
Praxical, ethical and aesthetic dimensions of teacher training: a \\ perspective in the light of Bakhtinian thought
}

\section{Diomar Caríssimo Selli Deconto}

Fernanda Ostermann ${ }^{2}$

\begin{abstract}
'Instituto Federal de Educação, Ciência e Tecnologia do Rio Grande do Sul (IFRS), Caxias do Sul, RS, Brasil. Autor Correspondente: diomar.deconto@caxias.ifrs.edu.br

${ }^{2}$ Universidade Federal do Rio Grande do Sul (UFRGS), Instituto de Física, RS, Brasil.
\end{abstract}

Resumo: Neste trabalho, apresentamos parte de uma pesquisa maior que tem por objetivo construir uma possível perspectiva de formação contra-hegemônica de professores de Ciências à luz do pensamento bakhtiniano, uma perspectiva que denominamos formação dialógica-responsável de professores. Três dimensões dessa perspectiva, práxica, ética e estética, serão desenvolvidas a partir do cotejamento de textos do Círculo Bakhtiniano com textos de formação de professores, sempre no sentido de tensionar, contrapor, mostrar insuficiências e avançar em relação ao modelo hegemônico de formação, pautado pela racionalidade técnica. Nossas dimensões permitem visualizar a formação docente de forma mais ampla, possibilitando novos olhares no que diz respeito à interdependência teoria-prática, a interrelações entre responsabilidade, valores e autonomia docente, bem como à função do professor como sujeito ativo, reflexivo e criador.

Palavras-chave: Formação docente; Bakhtin; Modelo de formação docente.

Abstract: In this paper, we present part of a larger research that aims to build a possible perspective of counter-hegemonic training of science teachers in light of Bakhtinian thought, a perspective that we call dialogical-responsible teacher training. Three dimensions of this perspective - praxical, ethical and aesthetic - will be pursued in the article by addressing Bakhtinian Circle texts and others on teacher training, always aiming at tensioning, countering, showing insufficiencies and advancing in relation to the hegemonic training model, guided by technical rationality. Our dimensions make it possible to visualize teacher training more broadly, allowing for new perspectives regarding the interdependence between theory and practice, the interrelationships between responsibility, values, and teacher autonomy, as well as the teacher's role as an active, reflective and creator subject.

Keywords: Teacher training; Bakhtin; Teacher training model.

Recebido em: 30/01/2021

Aprovado em: 01/09/2021 


\section{Introdução}

A predominância de um modelo de formação de professores que tem se mantido praticamente rígido desde sua concepção no início do século XX tem sido, frequentemente, denunciada pelas pesquisas da Educação e Educação em Ciências (GATTI, 2010; SAVIANI, 2009; SCHNETZLER, 2000). Tal modelo constitui-se como hegemônico na formação de professores (PEREIRA-DINIZ; ZEICHNER, 2017) e suas bases filosóficas encontram sustentação na concepção da racionalidade técnica, entendida como

A ideia básica do modelo de racionalidade técnica é que a prática profissional consiste na solução instrumental de problemas mediante a aplicação de um conhecimento teórico e técnico, previamente disponível, que procede da pesquisa científica. É instrumental porque supõe a aplicação de técnicas e procedimentos que se justificam por sua capacidade de conseguir os efeitos ou resultados desejados (CONTRERAS, 2012, p. 101).

Diante das inúmeras implicações negativas à formação, exaustivamente discutidas e criticadas pela literatura (GATTI, 2017; MALDANER, 2000; SCHNETZLER, 2000), provocadas por esse modelo hegemônico, faz-se necessário avançar nas análises e em construções teóricas capazes de contrapor e promover mudanças na formação dos professores. Neste sentido, partimos do pressuposto de que o pensamento bakhtiniano representa um referencial crítico e poderoso para refletir acerca da formação de professores, permitindo pensá-la em uma perspectiva de contra-hegemonia, uma vez que as ideias do Círculo Bakhtiniano" se caracterizam pelo pensamento do "contra" (TEZZA, 2001), no sentido de análise dos princípios fundamentais da teoria que vigora e sua reconstrução a partir das insuficiências identificadas.

Assim, neste trabalho, temos por objetivo discutir parte de um estudo mais amplo no qual construímos uma perspectiva de formação docente contra-hegemônica a partir do pensamento bakhtiniano. Nesse processo de construção emergiram dimensões (práxica, ética, estética, política, contextual e institucional, conhecimento e investigativa), decorrentes desse arcabouço teórico, constitutivas do que passamos a chamar "formação dialógica-responsável de professores" (DECONTO, 2020, p. 169).

Neste artigo, por limitação de espaço, desenvolvemos três (práxica, ética e estética) das sete dimensões construídas por meio do entrecruzamento entre pesquisas sobre formação docente e o pensamento bakhtiniano. Para os leitores desavisados, é preciso esclarecer que o Círculo não tratou do tema da formação docente, portanto, aí está a força da originalidade desta pesquisa de cunho teórico. Tal construção estruturase pelo princípio metodológico utilizado em alguns escritos do Círculo Bakhtiniano: o cotejamento (GERALDI, 2012), que significa dar contexto a um texto, colocá-lo em contato com outro texto (BAKHTIN, 2011), um contato dialógico que permite compreensões a partir de uma ação que contém o confronto e o encontro com o outro (ANDREIS, 2017), permitindo que vozes de um enunciado sejam mostradas/auscultadas e colocadas em relação interativa com outros enunciados, ampliando contextos (SCHERMA, 2017).

'Invenção apócrifa utilizada para se referir a um grupo não institucionalizado de intelectuais do qual Bakhtin fazia parte. Esse grupo, constituído também (mas não apenas) por Volochínov e Medvedev, promovia diálogos constantes e afinados em torno de pesquisas comuns, sob olhares e interesses diferentes. 


\section{Pensamento bakhtiniano e a formação de professores}

Uma forma mais estruturante de compreender as ideias do Círculo pode ser pelo que se chama de "grandes coordenadas" do pensamento bakhtiniano (FARACO, 2009), que fundamentam e permeiam todos os escritos desse grupo de intelectuais. Neste sentido, a discussão que apresentamos neste trabalho é guiada por essas três grandes coordenadas: unicidade e eventicidade do ser, o componente axiológico intrínseco ao ser humano e a contraposição eu/outro. Assim, um dos primeiros escritos de Bakhtin, Para uma filosofia do ato responsável (PFA), no qual esses pilares básicos aparecem de forma bastante explícita, norteia as reflexões acerca da formação docente e ajuda a entender, em parte, a formação dialógica-responsável de professores tratada, aqui, nesta produção.

Para compreender a noção de ato responsável é preciso destacar duas instâncias discutidas por Bakhtin (2010): o mundo da vida e o mundo teórico (ou da cultura). O mundo da vida é aquele repleto de eventos únicos, irrepetíveis, plenos, situados, dinâmicos: "[...] o mundo que cada um de nós cria, conhece, contempla, vive e morre" (BAKHTIN, 2010, p. 39). Este mundo, na visão do autor, confronta-se diretamente com o mundo da cultura ou teórico, dado como produto dos atos da vida (não conseguindo, entretanto, dar conta da irrepetibilidade e singularidade do mundo da vida), no qual se vislumbram as entidades repetíveis, genéricas, abstratas. Estes dois mundos, assim, são incomunicáveis e mutuamente impenetráveis, uma vez que se debruçam sobre planos em direções contrárias: um voltado para a unidade objetiva de um domínio da cultura e outro para a singularidade irrepetível da vida que se vive.

O pensamento teórico, ao tentar objetificar o mundo da vida, promove uma separação entre o conteúdo-sentido de um determinado ato e a realidade histórica do seu existir irrepetível, tornando o ato sem seu real valor, sem plenitude, sem existência, sem vida. A resposta a este impasse, à separação entre estes dois mundos, segundo Bakhtin (2010, p. 39), só encontra superação à medida que "[...] o ato encontra um plano unitário para refletir em ambas as direções, no seu sentido e em seu existir", que só se dará na unidade de uma responsabilidade. Ou seja, o ato responsável, fundado no reconhecimento da irrepetibilidade dos atos e na não exclusão do Ser, em toda sua processualidade e eventicidade, é a resposta para esta cisão, como um elemento que permite unir o singular e o universal.

A responsabilidade no pensamento bakhtiniano relaciona-se a uma dimensão valorativa que opera entre o conteúdo e o ato, permite, portanto, relacionar tanto o sentido como o seu fato, unir os aspectos universal e individual. Assim, o ato responsável exige uma espécie de assinatura-reconhecimento, que significa reconhecer-se como participante único e singular, uma posição que ninguém jamais poderá ocupar. Logo, a singularidade do existir é obrigatória, por isso não há álibi em existir, não há como fugir disso, ela implica Ser e, também, no dever, isto é, em algo que precisa ser realizado, que não é dado ou aprendido, mas "[...] algo que eu reconheço e afirmo de um modo singular e único" (BAKHTIN, 2010, p. 92, grifo do autor). 
O ato responsável é, precisamente, o ato baseado no reconhecimento desta obrigatória singularidade. É essa afirmação do meu não-álibi no existir que constitui a base da existência sendo tanto dada como sendo também real e forçosamente projetada como algo ainda por ser alcançado. É apenas o nãoálibi no existir que transforma a possibilidade vazia em ato responsável real (através da referência emotivo-volitiva a mim como aquele que é ativo). É o fato vivo de um ato primordial ao ato responsável, e a criá-lo, juntamente com seu peso real e sua obrigatoriedade; ele é o fundamento da vida como ato, porque ser realmente na vida significa agir, é ser não indiferente ao todo na sua singularidade. (BAKHTIN, 2010, p. 95, grifos nossos).

Ou seja, em função da sua unicidade, o ser não tem álibi para sua existência, o que o obriga a ser participante e a agir a tudo que para ele não é eu. Entretanto, isso não significa que o ser vive para si, mas relaciona-se ao outro em termos de não indiferença. Ao mesmo tempo, ao dizer que o ato é insubstituível em relação a tudo o que não é eu, Bakhtin está apontando que é apenas na relação com o outro que a unicidade do ser se realiza. Portanto, pode-se dizer que a responsabilidade pelo ato é uma responsabilidade para com o outro. Todavia, a noção de responsabilidade não é proposta por Bakhtin sob a ótica do determinismo, pois, como aponta, existe a possibilidade de abrir mão da responsabilidade do não-álibi no ser: "[...] podese ignorar a atividade e viver apenas da passividade, pode-se procurar demonstrar o próprio álibi no existir, pode-se ser impostor. Pode-se abdicar da sua obrigatória singularidade (da singularidade do próprio dever ser)" (BAKHTIN, 2010, p. 95).

Entretanto, viver na passividade é o mesmo que viver em um mundo de possibilidades, no qual a responsabilidade perde o sentido e, segundo Ponzio (2009), torna-se uma responsabilidade técnica, que se torna a mera representação de um papel, um mero desempenho técnico. Neste caso, não há ato responsável, mas apenas uma ação técnica: "[...] no fundamento do ato se encontra a sua incorporação na unidade singular: o responsável não se reduz ao especializado (a política), pois, caso contrário não teríamos um ato, mas uma ação [dejstvie] técnica" (BAKHTIN, 2010, p. 113).

A ação técnica relaciona-se ao que Bakhtin chama de crise do ato contemporâneo, pois criou-se um abismo entre o motivo do ato e o seu produto, levando à perda de sentido e à deterioração do produto. É interessante compreender essa questão a partir do que diferencia a ação do ato, como propõe Amorim (2009): a ação pode ser técnica ou tática, a primeira está voltada para a solução de questões práticas e imediatas, é pragmática; já a segunda escapa do domínio da ética, pois é um meio de combate para vencer o outro. Assim, “[...] a ação não é responsável, não tem assinatura, ao contrário, nela posso justamente visar apagar minha singularidade, fundir-me/confundir-me no que fazem e pensam os outros" (AMORIM, 2009, p. 39).

Neste sentido, propomos que o ato responsável do professor, quando este abre mão da sua responsabilidade, quando tenta escapar do seu não-álibi, vira ato técnico, vira ação, no sentido pragmático. Neste caso, a razão prática acaba subsumindo-se à razão teórica, e a ação do professor, de ordem técnica, descontextualizada, é voltada para a solução de questões que surgem na sala de aula a partir de técnicas rígidas, genéricas e objetivas oriundas do campo teórico, cuja definição se dá a partir de decisões de especialistas do meio acadêmico, isolados da situação concreta. A teoria determina a prática! Não é mais um ato responsável, mas uma ação de racionalismo técnico, pois o outro foi esquecido, as particularidades eliminadas em favor do que a academia condiciona como válido e eficiente para todos a partir de regularidades; 
não há assinatura do professor, o contexto concreto é indiferente para as soluções instrumentais a serem aplicadas em busca de metas pré-estabelecidas.

Assim, assumindo o ato responsável como um elemento que fundamenta a atividade docente (característico de uma formação contra-hegemônica), propomos que a fuga do não-álibi do professor, leva-o aos caminhos da racionalidade técnica (característico de uma formação hegemônica). Ou seja, a singularidade implica que o docente não tem álibi para sua existência no lugar que ocupa de ser professor, logo, é obrigado a agir responsavelmente. Por isso a centralidade do ato responsável na formação docente contra-hegemônica, pois se o professor foge do seu não-álibi, abdica da sua singularidade, o ato deixa de ser responsável e vira ação técnica, recai no racionalismo técnico. Neste sentido, o ato responsável de Bakhtin coloca-se como um elemento crucial no enfrentamento à formação docente hegemônica, pautada pela racionalidade técnica, proporcionando a emersão de dimensões formativas constituintes de uma perspectiva dialógica-responsável (contra-hegemônica) como as práxica, ética e estética, que desenvolvemos na sequência.

É necessário deixar claro que essas três dimensões não foram escolhidas aleatoriamente, sua presença nesse trabalho é derivada diretamente da noção de ato responsável. Ao assumir o ato responsável como elemento que fundamenta a atividade docente, emerge a questão da unidade entre os planos teórico-abstrato e práticosingular (que nos leva à ideia de práxis), que se dá em uma unidade de responsabilidade. Deste modo, estando a responsabilidade (e a responsividade) relacionadas ao agir ético do sujeito, emerge a ética bakhtiniana, referente a esse mundo da vida, fazendo referência ao âmbito das decisões do sujeito em relação ao agir concreto (que nos permite discutir sobre a ética na formação docente). Consequentemente, como o ético dialoga com o estético neste arcabouço teórico, na medida em que o segundo relaciona-se ao acabamento dado ao primeiro, emerge a questão estética na formação docente. Assim, não são coordenadas escolhidas aleatoriamente e nem estanques, mas dimensões diretamente relacionadas, imbricadas e articuladas, conforme discutiremos ao longo do texto.

\section{Dimensão práxica da formação docente}

A empreitada de Bakhtin de construir uma filosofia primeira, que leva em conta o evento como um acontecimento único, irrepetível e real, pauta-se, principalmente, por um posicionamento crítico ao racionalismo, que prioriza o universal em detrimento ao singular e possui um caráter puramente teórico, promovendo a objetivação e perda de vínculos com a historicidade dos atos, a separação entre o mundo teórico e o mundo da vida. Neste sentido, Bakhtin opõe a razão teórica à razão prática, considerando a primeira apenas como um momento da segunda, de forma que, como dito anteriormente, a superação da separação entre o mundo teórico e o mundo da vida se dá quando se subsumir a razão teórica na razão prática. Tal recondução do mundo teórico à razão prática não significa que Bakhtin invalide a cognição teórica. Muito pelo contrário, com esta proposta seu intuito é vincular, aproximar, reconciliar este mundo com o da vida. Desta forma, tal visão permite pensar, no que se refere à docência, em novos caminhos para a relação teoria-prática dos processos formativos, caminhos que permitam ir além da relação proposta pelo modelo da racionalidade técnica. 
A relação teoria-prática no modelo hegemônico, marcada por fragmentações e desarticulações, aponta para a proposição de momentos formativos separados: em um primeiro momento se dá conta da teoria e, posteriormente, da prática - em geral, ao final do curso, nos períodos de estágio. A teoria, nesse enquadramento, conforma a prática, conferindo-a o estatuto de aplicação do conhecimento sistematizado. Há, portanto, uma hierarquização entre estas duas instâncias no modelo formativo hegemônico, a teoria é supervalorizada e a prática desmerecida (DECONTO; CAVALCANTI; OSTERMANN, 2016). Como uma de suas consequências, tal dissociação, leva o professor, no momento de sua atuação futura, a agir como um executor técnico e não a agir responsavelmente.

O que o pensamento bakhtiniano permite visualizar, no que diz respeito à relação teoria-prática, é que não faz sentido uma formação docente pautada pela ênfase puramente teórica ou puramente prática, nem mesmo uma ênfase que mobilize ambas de forma igualitária se essas estiverem desarticuladas. Teoria e prática não deveriam seguir caminhos paralelos durante o processo formativo, sendo necessário que sejam contempladas em unidade, em comunhão, priorizando uma visão totalizante que tenha sempre como foco as situações concretas relacionadas ao fazer docente. A relação entre os mundos da cultura (teórico) e da vida (prático) é evidenciada em várias passagens de PFA. Por exemplo:

Todo o contexto infinito do conhecimento humano teórico possível - o da ciência - deve, para minha unicidade participante, tornar-se algo de responsavelmente reconhecido, o que não diminui nem deforma o que é verdade [istina] autônoma desse conhecimento, mas o completa até que se torne verdade ${ }^{2}$ [pravda] em sua validade compulsória (BAKHTIN, 2010, p. 104, grifo do autor).

Neste trecho é possível observar o empenho do autor em promover a aproximação entre o mundo teórico e o mundo da vida, ou, como diz Faraco (2009), o desejo de Bakhtin em reconciliar esses mundos. A teoria se vale do ato, complementa-se por ele, torna-se verdade (pravda). Já em uma passagem posterior, é possível identificar a proposição de que o ato necessita relacionar-se com a teoria, o ato também precisa da teoria. "Desde o momento em que a teoria se separa do ato e se desenvolve segundo a sua lei interna imanente, o ato mesmo, desembaraçando-se da teoria, começa a degradar-se" (BAKHTIN, 2010, p. 112). Também é possível vislumbrar tal preocupação do autor já no início de PFA, em que mostra a necessidade de considerar ambos aspectos ao fazer uma analogia do ato com o Jano bifronte, que aponta nas duas direções (plano teórico-abstrato e plano prático-singular).

Assim, com fundamento nessas ideias, é possível pensar a formação docente a partir de uma visão de prática ampliada, no sentido de que possa constituir uma unidade com a teoria, ou seja, a partir do pensamento bakhtiniano entendemos que a formação docente pode ser contemplada, como denominaremos aqui, por uma dimensão práxica. Esta dimensão remete à noção de práxis, que é uma atividade. Mas

\footnotetext{
${ }^{2}$ Bakhtin diferencia verdade (istina) de verdade (pravda). Verdade (istina) é aquela verdade associada ao racionalismo: universal, genérica, abstrata, definitiva, que se constrói na separação do momento do ato e seu conteúdo. Já a verdade (pravda) é a verdade singular, contingente, movente, apontando que, por ser produzida sobre o mundo concreto, não pode ser a mesma para todos em todos os momentos. Entretanto, elas não se estabelecem em termos de oposição, na medida em que o conhecimento abstrato, dado pela istina, é parcial, é o aspecto técnico do conhecimento último mas, quando inserido responsavelmente na singularidade, ao ser reconhecido e assinado, constitui a verdade situacional.
} 
não uma atividade qualquer, na medida em que é social, consciente e dirigida a um fim específico, diferentemente daquelas de caráter instintivo. Ou seja, práxis é

[...] uma atividade material transformadora e ajustada a objetivos. Fora dela fica a atividade teórica que não se materializa, na medida em que é atividade espiritual pura [mundo teórico na concepção bakhtiniana]. Mas, por outro lado não há práxis como atividade puramente material [sem unidade ao mundo teórico], isto é, sem a produção de finalidades e conhecimentos que caracteriza a atividade teórica (VAZQUEZ, 1968 apud SILVA, 2011, p. 22).

Assim, é possível dizer que a delimitação da práxis está nas relações estabelecidas entre teoria e prática, de forma que nesta concepção há três aspectos essenciais a se entender: o sujeito é um agente, que age no sentido de transformar o mundo; a teoria modifica-se no contato com a realidade; e a realidade reconfigura-se a partir da teoria.

Portanto, só na unidade entre teoria e prática pode haver uma práxis transformadora da realidade, pois é a teoria que possibilita, de modo indissociável, o conhecimento da realidade e o estabelecimento de finalidades para sua transformação. No entanto, para produzir tal transformação não é suficiente a atividade teórica; é preciso atuar praticamente sobre a realidade. (SILVA, 2011, p. 22).

Diante disso, essa dimensão práxica na formação docente ressalta a necessidade de constituir uma unidade entre teoria e prática, sem perder de vista a sala de aula, o mundo no qual os eventos relacionados à profissão docente irão ocorrer. Éa preocupação em manter correlacionados produto e processo, objeto e sujeito, em transitar entre o universal e o singular, em situar em torno da vida concreta, na qual o futuro professor deverá assumir seu papel social, seu compromisso com a transformação da realidade. Essa dimensão sugere ser essencial para minimizar as fragmentações dos processos formativos e para que o professor, no futuro, ao atuar, reconheça sua singularidade (e a do outro) e exerça o seu não-álibi, transformando possibilidades vazias em ato responsável.

Esse desdobramento das ideias do pensamento bakhtiniano para a formação docente encontra ressonância nas ideias do filósofo e educador Paulo Freire, uma vez que em sua filosofia também se vislumbra a necessária articulação teoria-prática desenvolvida a partir da noção de práxis pedagógica. Neste sentido, trazemos alguns elementos que permitem aproximar esses autores, de maneira a indicar a noção de práxis de Paulo Freire como um elemento potencialmente enriquecedor dessa dimensão da formação docente.

A práxis em Freire $(1987$, p. 21$)$ é vista como "[...] reflexão e ação dos homens sobre o mundo para transformá-lo, sem ela, é impossível a superação da contradição opressor-oprimidos", destacando que esta ação e reflexão se estabelecem juntas, pois "[...] não estamos propondo nenhuma dicotomia de que resultasse que este fazer se dividisse em uma etapa de reflexão e outra, distante, de ação. Ação e reflexão e ação se dão simultaneamente" (FREIRE, 1987, p. 72). Ou seja, é possível dizer que teoria e prática se estabelecem conjuntamente, em unidade, modificam-se e reconfiguram-se mutuamente. 
Com base nisso, entendemos existir uma estreita relação entre o conceito de práxis de Freire e ato responsável de Bakhtin, uma vez que ambos os conceitos são concebidos no sentido de superar o dualismo: teoria versus prática. Assim, afirma Freire

Mas, se os homens são seres do que fazer é exatamente porque seu fazer é ação e reflexão. É práxis. É transformação do mundo. E, na razão mesma em que o que fazer é práxis, todo fazer do que fazer tem de ter uma teoria que necessariamente o ilumine. O que fazer é teoria e prática. É reflexão e ação (FREIRE, 1987, p. 70, grifos nossos).

Portanto, é possível perceber que a noção de práxis em Freire se estabelece como uma atividade transformadora, que é ao mesmo tempo teórica e prática. A prática (ação) é guiada pela teoria (reflexão), assim como a teoria (reflexão) se reconfigura a partir da prática (ação), pois “[...] se o momento já é o da ação, esta se fará autêntica práxis se o saber dela resultante se faz objeto da reflexão crítica. [...] A não ser assim, a ação é puro ativismo" (FREIRE, 1987, p. 29-30, grifo nosso). Ou seja, quando não há práxis, no sentido de unidade entre teoria e prática, tem-se "verbalismo, blábláblá, palavreria" (FREIRE, 1987) ao se estabelecer a reflexão sem ação ou "ativismo puro" ao se estabelecer a ação sem reflexão (FREIRE, 1987). E, por outro lado,

\footnotetext{
[...] em sua definição de ato/atividade e evento, Bakhtin critica as tendências filosóficas, principalmente kantianas, que privilegiam o conteúdo do ato e desprezam seu processo, e as que vêem o processo em detrimento do conteúdo, e com base nisso propõe uma concepção que entende o ato como uma junção necessária de processo e conteúdo ou sentido, o que terá importantes consequências em suas teorias culturais como de filosofia da linguagem, de discurso, etc. (SOBRAL, 2005, p. 28).
}

Diante disso, o ato responsável parece guardar relações com a noção de práxis em Freire, no sentido de que existe apenas na união do momento singular da prática ao conteúdo-sentido teórico; uma atividade prática e teórica ao mesmo tempo: “[...] na sua responsabilidade, o ato coloca diante de si sua própria verdade [pravda] como verdade que une ambos os seus aspectos, assim como une o aspecto do universal (a validade universal) e do individual (o real)" (BAKHTIN, 2010, p. 77). Desta forma, entendendo que, quando o ato do professor se configura como ato responsável, aquele que ocorre quando o professor não abre mão do seu não álibi, estabelece-se uma verdadeira práxis pedagógica, no sentido freiriano. A partir desta noção freiriana, vislumbram-se possibilidades de superar a prática alienada e a instrumentalização teórica, em favor da unidade relacional dialética que concebe a construção de conhecimento a partir da reflexão crítica da prática e a ressignificação dos conhecimentos teóricos a partir da prática, cujo propósito máximo é a transformação da realidade e do ser humano.

\section{Dimensão ética da formação docente}

Como aponta Faraco (2009), a unicidade e eventicidade do ser, abordada ainda que não exaustivamente - nas reflexões desenvolvidas até o momento, é uma das três grandes coordenadas do pensamento bakhtiniano. Ao lado dessa, há outra grande coordenada que merece destaque: o componente axiológico intrínseco ao ser humano. Assim, um primeiro olhar, mais basilar, para a questão axiológica pode ser depreendido de PFA, no qual propõe-se que: 
Com o tom emotivo-volitivo indicamos exatamente o momento do meu ser ativo na experiência vivida, o vivenciar da experiência como minha: eu penso-ajo com o pensamento [...]. Para nós é importante relacionar uma dada experiência vivida a mim como aquele que a vive ativamente. Este relacionar a experiência a mim como ativo tem um caráter valorativo-sensorial e volitivo-realizador e é, ao mesmo tempo, responsavelmente racional. [...] O momento da atuação do pensamento, do sentimento, da palavra, de uma ação, é precisamente uma disposição minha ativamente responsável - emotivo-volitiva em relação à situação na sua totalidade, no contexto de minha vida real, unitária e singular (BAKHTIN, 2010, p. 87-88, grifos nossos).

Fica claro que, para o autor, todos os atos são constituídos por tons emotivovolitivos que, cabe ressaltar, de forma alguma, referem-se estritamente ao conteúdo em si, de forma isolada, mas na correlação com o sujeito no evento singular. O valor decorre da experiência ativa do sujeito, em situação concreta, e não pode ser entendido como um conjunto genérico e idêntico de valores que se impõem a ele. Da mesma forma, a valoração não se dá desvinculada dos outros sujeitos, isenta da alteridade. Diante desses apontamentos, ao agir, o sujeito constrói valores e, portanto, é possível afirmar que agir é valorar, como aponta Faraco (2009, p. 22):

[...] viver significa tomar uma posição axiológica em cada momento, significa posicionar-se em relação a valores. Vivemos e agimos, portanto, em um mundo saturado de valores, no interior do qual cada um de nossos atos é um gesto axiologicamente responsivo num processo incessante e contínuo.

Embora Bakhtin (2010) atribua centralidade ao sujeito ao considerá-lo centro emotivo-volitivo em torno do qual se estabelecem as relações no mundo ético, essa centralidade não pode ser entendida separada do "outro". É neste sentido que propõe que todos os valores reais da vida se dispõem em torno de três pontos fundamentais: eu-para-mim; outro-para-mim; eu-para-o-outro. Ou seja, como esclarece Ponzio (2009, p. 40), "[...] em Bakhtin os aspectos de tal arquitetônica, na qual são constituídos e arranjados todos os valores, significados e relacionamentos espaço-temporais, são caracterizados em termos da alteridade". Portanto, a alteridade, como terceira grande coordenada do pensamento bakhtiniano (FARACO, 2009), trata da contraposição eu/ outro, relação a partir da qual o ser constitui-se como tal, isto é, é apenas a partir do outro que o eu se constitui como sujeito.

O princípio arquitetônico supremo do mundo real do ato é a contraposição concreta, arquitetonicamente válida, entre eu e outro. A vida conhece dois centros de valores, diferentes por princípio, mas correlatos entre si: o eu e o outro, e em torno destes centros se distribuem e se dispõem todos os momentos concretos do existir (BAKHTIN, 2010, p. 138).

Assim, o eu não vive para si e todos os atos existem em função da contraposição axiológica com o outro. Dessa forma, a constituição do sujeito se dá de fora para dentro, tem um início e um fim, com o nascimento e a morte e, neste espaço cronológico, altera-se continuamente em busca de uma completude que nunca irá ocorrer. Desta forma, a partir das relações com o outro o eu busca completar-se, porém, a cada relação estabelecida surgem novos elementos que incompletam o eu, de forma que o estabelecimento de uma cópia entre o eu e o outro jamais acontecerá, pois, os lugares ocupados por eles são assimétricos, são diferentes. 
O eu e o outro são, cada um, um universo de valores. O mesmo mundo, quando correlacionado comigo ou com o outro, recebe valores diferentes, é determinado por diferentes quadros axiológicos. E essas diferenças são arquitetonicamente ativas, no sentido de que são constitutivas dos nossos atos (inclusive dos nossos enunciados): é na contraposição de valores que os atos concretos se realizam; é no plano dessa contraposição axiológica (é no plano da alteridade, portanto) que cada um orienta seus atos (FARACO, 2009, p. 22).

Neste sentido, propomos que a responsabilidade do professor não é uma responsabilidade genérica, ele é responsável por seus atos com relação ao outro, no caso, seus alunos (além de gestores, colegas, criadores de políticas públicas, etc.). Neste sentido, seus atos não são apenas responsáveis, mas também responsivos, isto é, sempre se relacionam ao outro e, por assim ser, respondem ao outro. Como aponta Bubnova (2016, p. 141), "[...] ser responsável é ser capaz de dar uma resposta: as duas qualidades do compromisso pessoal e de capacidade de resposta estão unidas na noção de responsabilidade [...]". Ou seja, como propõe Sobral (2005), um termo mais adequado para representar este conceito poderia ser "responsibilidade" que une ambos os aspectos que Bakhtin evidencia: a responsabilidade e a responsividade.

Portanto, com base no que apontamos até o momento, é razoável pensar que a ética ${ }^{3}$ representa outra possível dimensão dos processos formativos docentes na perspectiva do pensamento bakhtiniano, salientando que aqui não é a ética no sentido jurídico ou como conjunto de normas de conduta fixadas. A dimensão ética traz para o centro da discussão a dimensão do sujeito, reconhecendo o aspecto humano das ações do professor com relação ao outro, sempre singular. Na medida em que a prática docente se materializa por meio de uma série de interações com outros sujeitos, principalmente, os alunos, o professor não age sozinho e nem sobre objetos, mas em um contexto no qual seus atos envolvem diretamente o outro, o ser humano, singular, único.

Isso significa dizer, então, que a atuação do professor em sala de aula não se limita ao conhecimento técnico, neutro e indiferente ao contexto, sendo, intrinsecamente, permeada por valores éticos responsáveis por orientar escolhas e decisões que não são arbitrárias, mas fundadas na ética do professor, referente a princípios e a uma intencionalidade que têm como essência a presença do outro e a consequente responsabilidade para com ele. Dessa forma, vê-se a impossibilidade de o ato educativo ser axiologicamente neutro, uma vez que ao ensinar, o professor, se vale, mesmo que implicitamente, de escolhas valorativas.

Partindo do pressuposto de que a educação é, intrinsecamente, uma relação com os valores, Lucas, Passos e Arruda (2016) estudaram a influência dos valores na formação inicial de professores de Biologia. Em suas análises, os autores compreenderam que esses estudantes reproduzem o padrão valorativo dos seus professores, o que acaba mostrando, como uma das análises possíveis, que

[...] o processo de formação inicial de professores envolve considerar o papel dos sistemas de valores que interferem nesse processo, e que são capazes de revelar perfis profissionais gerados a partir das relações axiológicas estabelecidas entre estudantes e seus formadores (LUCAS; PASSOS; ARRUDA, 2016, p. 518).

\footnotetext{
3Ética em Bakhtin diz respeito ao mundo da vida, não é um conjunto de normas fixadas ou jurídicas, mas se refere a um modo de se relacionar com valores em situação concreta, se refere ao âmbito das decisões do sujeito em relação ao agir concreto.
} 
Logo, o professor não ensina apenas a matéria, mais do que isso, ensina um jeito de ser, uma forma de relacionar-se com o outro, ensina valores: "[...] a atitude do professor ensina. O gesto do professor fala" (RIOS, 2011, p. 83).

Assim, como permite refletir Rios (2010, 2011), a ética na educação, significa pensar: o que ensinamos quando ensinamos alguma coisa? Não basta saber bem e ensinar bem, "[...] não basta dominar bem os conceitos de sua área - é preciso pensar criticamente no valor efetivo desses conceitos para a inserção criativa dos sujeitos na sociedade" (RIOS, 2010, p. 108). A dimensão ética na formação docente, deste modo, não é reduzida à conduta profissional, ao que é certo ou errado, mas às responsabilidades do professor no campo da educação, para com seus alunos, sua instituição, sociedade em geral, evidenciando, como diz respeito ao mundo concreto, os efeitos do que faz/ diz nas outras pessoas. A ética, neste sentido, passa por tomar decisões que envolvem o outro e, portanto, também indica um modo de relacionar-se com valores, que longe de serem absolutos, passam por assumir contornos que envolvam a democracia, a justiça e a solidariedade.

Diante disso, é possível entender que essa dimensão da formação de professores relaciona-se ao que a literatura chama de autonomia docente. Como apontam Monteiro, Monteiro e Azevedo (2010, p. 119), “[...] a autonomia é o pressuposto e, ao mesmo tempo, o resultado da ética e, portanto, só pode ser definida na relação social". Tal elo é possível de ser estabelecido na medida em que se entende que a autonomia docente está relacionada a uma "[...] determinada forma de ser e estar de professores em relação ao mundo em que vive e atua como profissional, [...] ao falar da autonomia do professor, estamos falando também de uma relação com a sociedade [...]" (CONTRERAS, 2012, p. 29). Não desenvolveremos uma definição para o que viria a ser autonomia docente, uma vez que pode ser interpretada, compreendida e situada de diferentes maneiras de acordo com a perspectiva de profissional docente que é utilizada como lente. Todavia, independentemente dessas perspectivas, destacamos o fato de que a autonomia docente estabelece determinadas exigências (diferentes, de acordo a perspectiva em questão) sobre quais devem ser os âmbitos de decisão e responsabilidade do professor, influenciados por valores, compromissos e conhecimentos profissionais, sempre relacionados ao outro (CONTRERAS, 2012), o que, em nosso entendimento, tem seu desenvolvimento, não apenas, mas principalmente, inserido no contexto da dimensão ética da formação do professor.

\section{Dimensão estética da formação docente}

Um conceito diretamente ligado à alteridade é o da exotopia, uma vez que se relaciona ao necessário olhar de fora, distanciado, extralocalizado espaçotemporalmente, transgrediente, que apenas a partir do outro é possível obter, já que qualquer visão do eu a partir de si próprio seria distorcida, limitada, parcial. Por isso mesmo, os excedentes de visão e conhecimento são condicionados pela singularidade e insubstituibilidade do ser em seu lugar único no mundo, como aponta Bakhtin (2011, p. 21): 
Esse excedente da minha visão, do meu conhecimento, da minha posse - excedente sempre presente em face de qualquer outro indivíduo - é condicionado pela singularidade e pela insubstituibilidade do meu lugar no mundo: porque nesse momento e nesse lugar, em que sou o único a estar situado em dado conjunto de circunstâncias, todos os outros estão fora de mim.

E o outro, por estar fora do eu, consegue ver aquilo que é inacessível ao eu, assim como o eu consegue ver no outro aquilo que lhe é inacessível. Essa não coincidência de posições permite o excedente de conhecimento do eu em relação ao outro, permite que eu pratique ações em relação ao outro, "[...] a quem elas são inacessíveis no lugar que ele ocupa fora de mim; tais ações contemplam o outro justamente naqueles elementos em que ele não pode completar-se" (BAKHTIN, 2011, p. 23), de forma que a interrelação eu-outro minimiza as carências intrínsecas aos sujeitos. Neste sentido, Bakhtin aponta que é necessário entrar em empatia com o outro:

Eu devo entrar em empatia com esse outro indivíduo, ver axiologicamente o mundo de dentro dele tal qual ele o vê, colocar-me no lugar dele e, depois de ter retornado ao meu lugar, completar o horizonte dele com o excedente de visão que desse meu lugar se descortina fora dele, convertê-lo, criar para ele um ambiente concludente a partir do excedente da minha visão, do meu conhecimento, da minha vontade e do meu sentimento (BAKHTIN, 2011, p. 23).

Ou seja, há dois momentos importantes, em um primeiro momento o sujeito deve, em um processo de saída do eu, aproximar-se do outro e colocar-se (metaforicamente) no lugar dele, vivenciar o que ele vivencia e, em seguida, iniciar um processo de retorno para si, ao seu lugar fora do outro. Embora esse conceito tenha sido desenvolvido para discutir a relação entre o autor e a personagem na atividade estética, suas raízes podem ser encontradas já em PFA (AMORIM, 2009) e pode ser, como tentamos mostrar rapidamente aqui, utilizado para compreender as relações humanas, para compreender a própria constituição do sujeito, que exige a alteridade em busca de uma constante completude impossível. Além disso, em Geraldi (2007), é possível apreciar a transposição deste conceito para o mundo da vida e a proposição de que apesar deste último ser um mundo ético, a vida pode ser vivida esteticamente. Um possível desdobramento destes conceitos para a sala de aula é apontado por Geraldi (2013, p. 18):

Deslocado este conceito para a relação pedagógica, de imediato aparecem dois excedentes de visão que beneficiam um dos lados do par eu/tu: os excedentes de visão que tem o professor a respeito da continuidade do processo educativo (seus objetivos, suas finalidades, etc.) e o conhecimento excedente em relação ao que conhece o aluno. Por outro lado, como a relação pedagógica se funda na aprendizagem (e não no ensino que somente existe em função desta), o professor depende crucialmente do aluno, para sua completude e sucesso como professor: do que ele conhece (onde ancorará o novo) e de seu engajamento no projeto de futuro que Ihe é exposto em cada gesto, em cada conteúdo, pois é o compromisso com o futuro que justifica a própria existência da relação pedagógica.

Portanto, ao professor, tendo em vista um ensino preocupado com a aprendizagem, cabe colocar-se no lugar do outro, principalmente do aluno, que é o sujeito principal dos processos educativos, mas não apenas, como também no lugar dos demais elementos constituintes do ambiente escolar, como o colega professor, o 
supervisor educacional, os pais, etc. Buscar empatia para com o outro, vislumbrar o que este constrói ou não com relação ao algo a ser alcançado no processo de educação, situar-se no contexto de vida que embasa o olhar do outro para a escola, para o professor e para disciplina a ser aprendida, são exemplos de elementos essenciais que o professor, comprometido com uma educação pautada pela responsabilidade, não pode tratar com indiferença e que podem ser conhecidos por movimentos exotópicos. Como esclarece Geraldi (2007, p. 45):

Enquanto a posição exotópica ocupada pelo Outro lhe permite um excedente de visão, pelo qual também nos orientamos na busca de completude e acabamento, o próprio sujeito desloca-se, no tempo, e estabelece no futuro a razão de ser de sua ação presente que, concretizada, torna-se pré-dado para futuras ações, sempre orientadas pelo sentido que concebe a razão perpetuamente situada à frente.

O autor chama atenção, neste sentido, para o fato de as ações dos sujeitos estarem orientadas a partir do futuro, o que significa que é com uma imagem do futuro que se qualificam as ações do presente. É o que em Bakhtin (2011) aparece como memória de futuro. Esta memória de futuro, este por-vir imaginado, juntamente com a situação do presente, limita o cálculo de possibilidades a partir do qual será definida/ escolhida uma determinada ação do ser, tendo em vista construir um acabamento ao imaginado.

O acabamento é um componente essencialmente estético, embora, como se pode perceber, imbricado com o mundo ético. Em O autor e a personagem na atividade estética (BAKHTIN, 2011) o excedente de visão é o elemento necessário para que o autor-criador dê acabamento ao personagem. Assim, no mundo estético, o mundo da criação, o autor-criador, a partir de um posicionamento valorativo, dá forma ao conteúdo, isola aspectos de eventos do mundo da vida e os organiza de uma nova forma e dá acabamento a eles (FARACO, 2005). Por outro lado, no mundo da vida nunca há um acabamento definitivo, há uma memória de futuro, não muito rígida, que dá direcionamento às ações dos sujeitos. "Por isso, no mundo da vida estamos sempre calculando possibilidades e escolhemos uma delas no leque que se nos apresenta em função do futuro (acabamento provisório) de que temos memória" (GERALDI, 2013, p. 19).

Nesse sentido, o ato pedagógico tem algo de estético, necessariamente: antevê (ou transvê, para usar a expressão do poeta Manoel de Barros) um acabamento provisório no futuro, dele tem uma memória, e com essa memória calcula as ações possíveis no presente com o material que nos fornece o passado, mas selecionados para realizar o futuro: saberes, conhecimentos, crenças, utopias, etc. (GERALDI, 2013, p. 19-20).

Portanto, propomos que a atividade docente, além de ser um ato ético, possui também um caráter estético: é uma atividade de criação, na qual o professor, ancorado nos excedentes de visão e conhecimento que possui sobre seus alunos, sobre a realidade escolar, sobre o conteúdo, sobre o tempo em que se situa e sobre o tempo futuro (memória de futuro), assume um posicionamento valorativo, faz recortes necessários, enforma e cria suas 'obras de arte' em sala de aula. Claro que essa estética difere daquela referente ao mundo da arte, pois esse acabamento dado pelo professor 
na vida cotidiana é sempre um acabamento provisório e fragmentário, de pequenos eventos particulares, enquanto no mundo da arte o acabamento relaciona-se ao todo integral.

Trazer a dimensão estética para a formação docente significa conceber o professor como um sujeito ativo, participante e criador. Diante disso, visualizando a docência sob estas características, pode-se dizer que o pensamento bakhtiniano permite conceber uma visão que vai de encontro ao que propõe a racionalidade técnica, uma vez que, de acordo com este referencial, a prática docente envolve também a criação, fruto de olhares exotópicos únicos e de contextos diferentes e mutáveis, logo, jamais poderia ser concebida de forma técnica, pronta, indiferente ao outro. Neste sentido, com uma visão que parece coerente ao pensamento bakhtiniano, Rios (2010) ajuda a iluminar o entendimento dessa dimensão na docência:

Afirmar uma dimensão estética na prática docente é trazer luz para a
subjetividade do professor, subjetividade construída na vivência concreta
do processo de formação e de prática profissional. É necessário considerar,
também, que [...]. Subjetividade se articula com identidade, que é afirmada
exatamente na relação com alteridade, com a consideração do outro (RIOS,
2010, p. 68).

Diante disso, é possível questionar a tendência do modelo hegemônico de formação docente em assumir uma perspectiva prescritiva, isto é, de propor métodos e técnicas prontos e acabados de ensinar em sala de aula. Por isso, refletimos que a formação docente poderia ser permeada por uma dimensão estética, na qual o futuro professor fosse capaz de visualizar a docência como potencial de criação, sensível ao outro, e não como aplicação de receitas pedagógicas para ensinar, como reprodução. A reprodução não dá conta das situações de sala de aula que, por serem extremamente dinâmicas, envolvem a solução de problemas únicos daquele contexto, a capacidade de reflexão e de improvisação, exigem que o professor tenha condições de, além de agir responsavelmente, criar.

Neste sentido, essa dimensão, que guarda relações diretas com a noção de prática, enfatiza a necessidade de a formação priorizar momentos de exotopia na prática pedagógica, movimento este que se constituirá fundante da futura atuação docente. Isto é, entendemos que o professor precisa deslocar-se do seu papel e visualizar sua própria prática de um ponto extralocalizado para, neste movimento, ter uma visão outra, que Ihe permita refletir sobre a prática, pensar como resolver determinados problemas, ir exercitando sua capacidade de improvisação, trilhando um caminho que se aproxime do flexível e se afaste do rígido - que não se refere a rigor, como esclarece Geraldi (2013). Neste quesito, então, deslocam-se características formativas tradicionalmente associadas ao modelo de professor enquanto racionalista técnico em direção ao modelo de professor como profissional reflexivo.

Neste sentido, esta dimensão mostra-se relevante também para discutir o papel do professor formador nos processos formativos. Por isso, como apontam Viveiro e Campos (2014, p. 225):

É importante destacar, no entanto, que o posicionamento dos docentes que atuam nos cursos de licenciatura é decisivo no perfil do professor a ser formado. Afinal, são eles que colocam em prática o currículo e é pela atuação do grupo de docentes, a partir da 'leitura' que fazem da proposta de um curso, que se configura a perspectiva de ensino predominante. 
Ou seja, é a memória de futuro projetada pelo conjunto de formadores que permitirá dar os necessários acabamentos no decorrer do processo formativo em direção ao perfil de professor que se deseja formar. Assim, não basta ter um currículo estruturado com um viés que vise superar perspectivas hegemônicas se a leitura deste currículo feita pelos formadores não estiver alinhada a tal pressuposto, e se não houver uma organização coesa por parte desses formadores, comprometida com a memória de futuro projetada. Inclusive, esta memória de futuro implica, necessariamente, coerência entre o que se faz na formação e o que se espera do futuro professor. Ou seja, a forma como se dá a formação do futuro professor não pode ser incoerente com aquilo que se espera dele no momento de sua atuação futura. Certamente um dos olhares exotópicos que o estudante irá realizar em sua prática futura, quando for professor, envolverá o deslocamento para o espaço-tempo do seu processo formativo, a partir do qual buscará conhecimentos nas concepções de ensino e aprendizagem aí desenvolvidas, nas críticas e reflexões efetuadas, nas metodologias construídas, entre outros, mas, principalmente, ainda mais nos primeiros anos, no modo de atuação de seus formadores.

Como forma de sintetizar as discussões desenvolvidas nas seções anteriores, apresentamos no quadro 1 uma síntese com as dimensões da formação dialógicaresponsável de professores aqui apresentadas. Isto é, apresentamos dimensões da formação contra-hegemônica que elementos do pensamento bakhtiniano nos permitiram construir, que, embora expostas de maneira esquemática, não são possíveis de serem pensadas umas sem as outras e nem suas constituições são independentes.

Quadro 1 - Dimensões práxica, ética e estética da formação dialógica-responsável

\begin{tabular}{|c|c|c|}
\hline Dimensão & Conceitos relacionados & Descrição resumida \\
\hline Práxica & $\begin{array}{l}\text { Ato responsável; } \\
\text { Unicidade e eventicidade do ser; } \\
\text { Não-álibi na existência; } \\
\text { Razão teórica e razão prática. }\end{array}$ & $\begin{array}{l}\text { Formação contempla teoria e prática em unidade, preocupa-se em } \\
\text { manter correlacionados produto e processo, objeto e sujeito, em } \\
\text { transitar entre o universal e o singular, em situar em torno da vida } \\
\text { concreta, na qual o futuro professor deverá assumir seu papel social, } \\
\text { seu compromisso com a transformação da realidade. }\end{array}$ \\
\hline Ética & $\begin{array}{l}\text { Ato responsável; } \\
\text { Responsabilidade; } \\
\text { Componente axiológico intrínseco ao ser } \\
\text { humano; } \\
\text { Alteridade; } \\
\text { Ética. }\end{array}$ & $\begin{array}{l}\text { Coloca a centralidade no sujeito, permitindo reconhecer o aspecto } \\
\text { humano dos atos do professor com relação ao outro. Implica uma } \\
\text { visão de que a atuação do professor em sala de aula não se limita } \\
\text { ao conhecimento técnico, neutro e indiferente ao contexto, sendo, } \\
\text { intrinsecamente, permeada por valores éticos responsáveis por orientar } \\
\text { escolhas e decisões que não são arbitrárias, mas fundadas na ética do } \\
\text { professor, referente a princípios e a uma intencionalidade que têm } \\
\text { como essência a presença do outro e a consequente responsabilidade } \\
\text { para com ele. Assim, incide diretamente sobre a questão da autonomia } \\
\text { docente, considerada pressuposto e resultado da ética. }\end{array}$ \\
\hline Estética & $\begin{array}{l}\text { Alteridade; } \\
\text { Exotopia-excedentes de visão e conheci- } \\
\text { mento; } \\
\text { Memória de futuro; } \\
\text { Horizonte de possibilidades; } \\
\text { Acabamento; } \\
\text { Estética. }\end{array}$ & $\begin{array}{l}\text { Promove deslocamentos que aportam nuances do professor como } \\
\text { profissional reflexivo, como sujeito que cria, participa, tem capacidade } \\
\text { de reflexão e improvisação. Aponta para a necessidade de a formação } \\
\text { superar a visão prescritiva de modelos e métodos a serem aplicados, } \\
\text { em favor de uma visão mais aberta às incertezas do ato de ensinar, } \\
\text { que respeite a presença da alteridade e possibilite caminhos para criação, } \\
\text { construção, flexibilidade, sensibilidade e, principalmente, independência } \\
\text { da implementação rígida e inquestionável ao dado e fechado fornecido } \\
\text { pelos especialistas. }\end{array}$ \\
\hline
\end{tabular}

Fonte: Deconto (2020).

\section{Conclusão}

Neste trabalho, refletimos sobre formação docente, de uma maneira original em nossa área, a partir do pensamento bakhtiniano, sempre no tensionamento com o modelo hegemônico, pautado pela racionalidade técnica. Como mostramos em 
Deconto e Ostermann (2020), os trabalhos com o pensamento bakhtiniano na área de Educação em Ciências estão mais focados em aplicar, muitas vezes mecanicamente, como categorias, os conceitos desse arcabouço teórico do que pensar a partir das ideias do Círculo. Este é um dos sentidos pelos quais entendemos estar propondo uma pesquisa bastante original em nossa área, uma vez que buscamos refletir, pensar a partir do pensamento bakhtiniano, trazendo-o constantemente para iluminar a produção de conhecimento, colocando-o em correlação com outros textos, com outros campos, com outros objetos de estudo.

Apresentamos, neste artigo, algumas dimensões características do que chamamos de formação dialógica-responsável de professores (que terá seu desenvolvimento pleno completado em publicação posterior). Tal construção (parcialmente apresentada) não tem o objetivo de ser uma teoria de formação docente bakhtiniana, nem um modelo de formação; não estamos aqui estipulando uma prescrição para a formação docente, conteúdos que devem ser contemplados, a forma como deveriam ser contemplados ou a forma como a formação deveria ocorrer. Apresentamos uma perspectiva (dentre outras que podem vir a existir com base nesse referencial) que contém reflexões nossas a partir da forma de ver o mundo, apreendida do pensamento bakhtiniano, que pode contribuir para a constituição de formações contra-hegemônicas.

Cabe ressaltar que as dimensões abordadas não são estanques, arbitrárias ou mecânicas. São produto da teorização desenvolvida a partir do conceito de ato responsável no contexto da formação de professores, que articula todas elas entre si, como um todo arquitetônico e não mecânico. Logo, essas dimensões estão correlacionadas, há organicidade entre elas.

A partir dessas dimensões, entendemos que a perspectiva de formação dialógica-responsável de professores traz contribuições complementares e também que avançam em relação a outras abordagens já consagradas. Por exemplo, além de percorrer questões similares às teorias críticas, como ideologia, poder, relações sociais, emancipação e resistência (DECONTO, 2020), o pensamento bakhtiniano, como foi possível perceber no desenvolvimento dessas três dimensões, lança-se sobre temas como identidade, alteridade, diferença, subjetividade, discurso e cultura, que flertam com as teorias pós-críticas. Assim, considerando ser impossível classificar o pensamento bakhtiniano em qualquer corrente, percebemos que, neste caso específico, ele se situa em uma zona fronteiriça que mostra sua originalidade e seu potencial de avançar em relação às discussões sobre a formação docente. Outro aspecto que traz implicações novas acerca da formação de professores é a dimensão estética. Como elemento da formação docente, a questão da estética sempre parece estar presente em propostas mais progressistas de formação, no entanto, as pesquisas nunca dedicam a ela uma discussão mais profunda e teórica como fizemos neste trabalho. Estudos em um referencial que contempla discussões profundas sobre estética em articulação com a ética e a cognição, como o pensamento bakhtiniano, ainda não se fazem presentes na produção acadêmica em Educação em Ciências.

Por fim, cabe ressaltar que as dimensões aqui desenvolvidas permitem repensar, transformar, dar encaminhamentos, estruturar formações que rompam com o modelo hegemônico de formação. Esse entendimento acerca das reflexões expostas se dá justamente pelo fato de estabelecerem uma perspectiva construída em um 
movimento de crítica ao modelo hegemônico, a partir da revisão de seus pressupostos fundamentais, revelando, neste movimento, pelo tensionamento com outros textos, insuficiências e contradições que nos permitiram, mesmo que não de forma plena, reconstruir a partir de uma outra visão, originada pela nossa compreensão ativa das ideais do Círculo.

\section{Referências}

AMORIM, M. Para uma filosofia do ato: "válido e inserido no contexto". In: BRAIT, B. (org.). Bakhtin: dialogismo e polifonia. São Paulo: Contexto, 2009. p. 17-44.

ANDREIS, A. M. Cotejo e confroencontro. In: GRUPO DE ESTUDOS DOS GÊNEROS DO DISCURSO. (org.). Palavras e contrapalavras: entendendo o cotejo como proposta metodológica. São Carlos: Pedro \& João, 2017. p. 11-16.

BAKHTIN, M. O autor e a personagem na atividade estética. In: BAKHTIN, M. Estética da criação verbal. 6. ed. São Paulo: WMF Martins Fontes, 2011. p. 3-194.

BAKHTIN, M. Estética da criação verbal. 6. ed. São Paulo: WMF Martins Fontes, 2011.

BAKHTIN, M. Para uma filosofia do ato responsável. São Carlos: Pedro \& João, 2010.

BUBNOVA, T. "Do corpo à palavra": um itinerário bakhtiniano. In: BUBNOVA, T. Do corpo à palavra: leituras bakhtinianas. São Carlos: Pedro \& João, 2016. p. 121-162.

CONTRERAS, J. Autonomia de professores. 2. ed. São Paulo: Cortez, 2012.

DECONTO, D. C. S. Pensamento bakhtiniano e perspectivas críticas: elementos para uma formação contra-hegemônica de professores de ciências. 2020. Tese (Doutorado em Ensino de Física) Instituto de Física, Universidade Federal do Rio Grande do Sul, Porto Alegre, 2020. Disponível em: http://hdl.handle.net/10183/218430. Acesso em: 6 out. 2021.

DECONTO, D. C. S.; CAVALCANTI, C. J. H.; OSTERMANN, F. Incoerências e contradições de políticas públicas para formação docente no cenário atual de reformulação das diretrizes curriculares nacionais. Caderno Brasileiro de Ensino de Física, Florianópolis, v. 33, n. 1, p. 194-222, 2016. DOI: https://doi.org/gzmf.

DECONTO, D. C. S.; OSTERMANN, F. Educação em ciências e pensamento bakhtiniano: uma análise de trabalhos publicados em periódicos nacionais. Revista Brasileira de Pesquisa em Educação em Ciências, Belo Horizonte, v. 20, p. 121-156, 2020. DOI: https://doi.org/gzmg.

FARACO, C. A. Autor e autoria. In: BRAIT, B. (org.). Bakhtin: conceitos-chave. São Paulo: Contexto, 2005. p. 37-60.

FARACO, C. A. Linguagem \& diálogo: as ideias linguísticas do círculo de Bakhtin. São Paulo: Parábola, 2009.

FREIRE, P. Pedagogia do oprimido. Rio de Janeiro: Paz e Terra, 1987.

GATTI, B. A. Formação de professores, complexidade e trabalho docente. Revista Diálogo Educacional, Curitiba, v. 17, n. 53, p. 721-737, 2017. DOI: https://doi.org/gzmm.

GATTI, B. A. Licenciaturas: crise sem mudança? In: DALBEN, Â.; DINIZ-PEREIRA, J. E.; LEAL, L. F. V.; SANTOS, L. L. C. P. (org.). Convergências e tensões no campo da formação docente: didática, formação de professores e trabalho docente. Belo Horizonte: Autêntica, 2010. p. 485-508.

GERALDI, J. W. Bakhtin tudo ou nada diz aos educadores: os educadores podem dizer muito com Bakhtin. In: FREITAS, M. T. A. (org.). Educação, arte e vida em Bakhtin. Belo Horizonte: Autêntica, 2013. p. 11-28. 
GERALDI, J. W. A diferença identifica. A desigualdade deforma. Percursos bakhtinianos de construção ética e estética. In: FREITAS, M. T. A.; JOBIM, S.; KRAMER, S. (org.). Ciências humanas e pesquisa: leitura de Mikhail Bakhtin. 2. ed. São Paulo: Cortez, 2007. p. 39-56.

GERALDI, J. W. Heterocientificidade nos estudos linguísticos. In: GRUPO DE ESTUDOS DOS GÊNEROS DO DISCURSO. (org.). Palavras e contrapalavras: enfrentando questões da metodologia bakhtiniana. São Carlos: Pedro \& João, 2012. p. 19-39.

LUCAS, L. B.; PASSOS, M. M.; ARRUDA, S. M. A não neutralidade axiológica do processo de formação inicial de professores de biologia. Revista Brasileira de Pesquisa em Educação em Ciências, Belo Horizonte, v. 16, n. 3, p. 499-520, 2016. Disponível em: https://periodicos.ufmg.br/ index.php/rbpec/article/view/4475. Acesso em: 15 ago. 2021.

MALDANER, O. A. A formação inicial e continuada de professores de química. ljuí: Ed. Unijuí, 2000.

MONTEIRO, M. A. A.; MONTEIRO, I. C. C.; AZEVEDO, T. C. A. M. Visões de autonomia do professor e sua influência na prática pedagógica. Ensaio: pesquisa em educação em ciências, Belo Horizonte, v. 12, n. 3, p. 117-130, 2010. DOl: https://doi.org/gzmn.

PEREIRA-DINIZ, J. E.; ZEICHNER, K. M. A pesquisa na formação e no trabalho docente. São Paulo: Autêntica, 2017.

PONZIO, A. A revolução bakhtiniana. São Paulo: Contexto, 2009.

RIOS, T. A. Compreender e ensinar: por uma docência de melhor qualidade. 8. ed. São Paulo: Cortez, 2010.

RIOS, T. A. A dimensão estética na sala de aula ou o que nós fazemos com eles. In: PEREIRA, E. M. A.; ALMEIDA, M. L. P. (org.). Reforma universitária e a construção do espaço europeu de educação superior: uma análise de uma década do processo de Bolonha. Campinas: Mercado de Letras, 2011. p. 73-93.

SAVIANI, D. Formação de professores: aspectos históricos e teóricos do problema no contexto brasileiro. Revista Brasileira de Educação, Rio de Janeiro, v. 14, n. 40, p. 143-155, 2009. DOI: https:// doi.org/d46pmg.

SCHERMA, C. C. A insondabilidade e o cotejamento como caminhos metodológicos e de compreensão. In: GRUPO DE ESTUDOS DOS GÊNEROS DO DISCURSO. Palavras e contrapalavras: entendendo o cotejo como proposta metodológica. São Carlos: Pedro \& João, 2017. p. 198-211.

SCHNETZLER, R. P. O professor de ciências: problemas e tendências de sua formação. In: SCHNETZLER, R. P.; ARAGÃO, R. M. R. (org.). Ensino de ciências: fundamentos e abordagens. Campinas: R. Vieira, 2000. p. 12-41.

SILVA, K. A. C. P. C. A formação de professores na perspectiva crítico-emancipadora. Linhas Críticas, Brasília, v. 17, n. 32, p. 13-31, 2011. DOI: https://doi.org/gzmp.

SOBRAL, A. Ato/atividade e evento. In: BRAIT, B. (org.). Bakhtin: conceitos-chave. São Paulo: Contexto, 2005. p. 11-36.

TEZZA, C. Sobre "o autor e o herói": um roteiro de leitura. In: FARACO, C. A.; TEZZA, C.; CASTRO, G. (org.). Diálogos com Bakhtin. Curitiba: Editora da UFPR, 2001. p. 273-304.

VIVEIRO, A.; CAMPOS, L. Formação inicial de professores de ciências: reflexões a partir das abordagens das estratégias de ensino e aprendizagem em um curso de licenciatura. Alexandria, Florianópolis, v. 7, n. 2, p. 221-249, 2014. Disponível em: https://periodicos.ufsc.br/index.php/ alexandria/article/view/38225. Acesso em: 15 ago. 2021. 